\title{
Wind Flow Conditions as an Indicator to Assimilative Capacities of Urban Airsheds towards Atmospheric Pollution Potential
}

\author{
Manju Mohan* and Shweta Bhati \\ Centre for Atmospheric Sciences, Indian Institute of Technology Delhi, New Delhi, India
}

\begin{abstract}
Wind flow conditions play an important role in the assimilative capacities of urban airsheds. It is desired that urban planners associate due importance to wind flow conditions while designing the cities considering its likely impact on ambient air quality.

Further, considering the explosive growth of megacities across the world it is required to rank these cities as per their assimilative capacities where wind flow conditions can play an important role. This study scrutinizes wind flow conditions (stagnation, ventilation and recirculation), associated air quality and emissions for two megacities namely, Delhi and Mumbai to illustrate the pivotal role, the meteorology could play in location of urban airsheds. The study shows a dominance of stagnation conditions with few cases of recirculation events over Delhi. Ambient levels of pollutants were found to correlate positively with stagnation conditions in Delhi. Mumbai was found to have higher ventilation and recirculation events and lower ambient levels of the pollutants. Further, this study for two megacities demonstrated that persistently poor air flow conditions for an urban airshed could lead to poorer air quality even with lower emissions (Delhi) in comparison to a city with lower pollution potential and higher emissions (Mumbai). Simple methodologies as adopted here could be practiced to scrutinise carrying capacities of the cities and to rank these for their pollution potential that could be helpful to regulators for emission control strategies.
\end{abstract}

Keywords: Stagnation; Ventilation; Air quality; Carrying capacity; Megacities

\section{Introduction}

Stagnation, recirculation and ventilation are terms that indicate special types of flow conditions that have important consequences for the dispersion of air pollutants. The concepts of stagnation and recirculation as measures for characterizing the air pollution transport potential of an air-shed were introduced by Allwine and Whiteman [1]. Stagnation refers to events where atmospheric flows decrease in speed, or stop altogether, allowing pollutants to build up in stagnant air in the vicinity of the pollutant sources. In recirculation events polluted air is initially carried away from the source but later returns to produce a high pollution episode. Ventilation, on the other hand, indicates those events in which polluted air is replaced or diluted by fresh air [1]. Thus an urban air-shed prone to stagnation and recirculation events has high potential for air pollution episodes.

The events of ventilation, stagnation and recirculation have been analysed in the past. Allwine and Whiteman [1] analysed the ventilation, stagnation and recirculation events using three months of hourly surface measurements of horizontal wind speed and direction in the Colorado Plateaus Basin region of Arizona during the winter of 1990. The occurrence of stagnations, recirculations and ventilations in the atmosphere of five urban and industrial areas in the Argentine Republic was computed by Venegas and Mazzeo [2]. Kim et al. [3], investigated the suitability of four locations in Korea for nuclear power sites from meteorological point of view by estimating the integral quantities related to the occurrence of stagnations, recirculations and ventilations. Nankar et al. [4], studied seasonal occurrence of stagnation, recirculation and ventilation characteristics at Kakrapar Atomic Power Station, India. Zhao et al. [5], analysed ventilation and stagnation events in California's San Joaquin Valley area using WRF modeling system. Studies related to pollution episodes and staganation conditions have been undertaken in recent past [6-8].

Thus, wind flow conditions studies can be useful to evaluate the pollution potential of various urban airsheds and also help in assessing the assimilative capacities of different environments. Wind flow conditions can be critically examined for assessing the dispersal capabilities of the atmosphere. A methodology in this study is demonstrated with a case study in this respect. In this study, the concentration levels of various air pollutants are analysed in terms of wind flow conditions over an urban airshed (Delhi) and further comparison of two megacity urban airsheds (Delhi and Mumbai) are made in terms of their emissions and assimilative capacities of the ambient atmosphere. The previous studies have mostly focused only on wind flow conditions while the present study finds linkages of these with emission scenarios to demonstrate that it is possible to ascertain and rank the assimilative capacities of the various urban airsheds a-priori before the developmental activities are considered for these urban airsheds.

\section{The study area and data}

The capital city of Delhi and its surroundings rank amongst the most populated urban agglomerations of the world [9]. The rapid progress witnessed in the city, however, has made it one of the highly polluted megacities of the world. Exceedences of prescribed ambient concentration standards for pollutants like $\mathrm{NO}_{2}, \mathrm{PM}_{10}$ and $\mathrm{PM}_{25}$ are frequently reported in the city $[10,11]$. Atmospheric pollution in Delhi often leads to poor air quality indices for many areas of the city [12] and its impact on health has also been explored in earlier exposure assessment studies $[13,14]$. Emission sources and hotspots have been identified in the city in many earlier studies [15-17]. However, other than emissions,

*Corresponding author: Manju Mohan, Centre for Atmospheric Sciences, Indian Institute of Technology Delhi , India; Tel: 91-11-26591313; Fax: 91-11-26591386; E-mail:mmohan6@hotmail.com

Received September 06, 2012; Accepted October 01, 2012; Published October 15,2012

Citation: Mohan M, Bhati S (2012) Wind Flow Conditions as an Indicator to Assimilative Capacities of Urban Airsheds towards Atmospheric Pollution Potential. J Civil Environ Eng S1:003. doi:10.4172/2165-784X.S1-003

Copyright: $\odot 2012$ Mohan M, et al. This is an open-access article distributed under the terms of the Creative Commons Attribution License, which permits unrestricted use, distribution, and reproduction in any medium, provided the original author and source are credited. 
dispersion of pollutants in air is an equally significant determinant of ambient concentrations. Atmospheric flow characteristics have a dominant influence over the dispersion phenomena. Hence, factors related to transport of air pollutants is important to understand the assimilative capabilities of the city environments.

The capital city of Delhi is located at latitude $28^{\circ} 38^{\prime} 17^{\prime \prime} \mathrm{N}$ and longitude $77^{\circ} 15^{\prime} 51^{\prime \prime} \mathrm{E}$ with an altitude of $215 \mathrm{~m}$ above sea level (Figure 1). With a population of about 13.85 million [18], it is one of the rapidly growing megacities in the world. The summer season (April, May and June) is governed by high temperature and hot, high speed winds. The monsoon (July, August and first half of September) is dominated by rains and high humidity levels in air. The winter season starts in late November and ends with the month of early February. This period is dominated by cold, dry air and ground-based inversion with low wind conditions. The months of February and March are also referred to as spring period and the months of October and November are sometimes designated as post monsoon months [19].

Mumbai, the capital city of state of Maharashtra is the largest metropolis of the country [20]. It is a tropical coastal city $\left(18^{\circ} 58^{\prime} \mathrm{N}, 72^{\circ}\right.$ $49^{\prime}$ E) with lesser seasonal variations as compared to Delhi. Mumbai has a tropical wet and dry climate. The city, being in the tropical zone and near the Arabian Sea, does not experience distinct seasons, but the climate can broadly be classified into two main seasons: the humid season (March - October) and the dry season (November - February). The annual temperatures range from a high of $38^{\circ} \mathrm{C}$ to a low of $11^{\circ} \mathrm{C}$ while city's annual rainfall is about $2,200 \mathrm{~mm}$ [21].

The data used in the study is for a period of about six months i.e. from December 2007 to May 2008. This period can be considered to span over three seasons: Winter (Dec-Jan), Spring (Feb-Mar) and Summer (Apr-May). For Delhi, 1-hour average data of wind speed and direction has been obtained from the WatchDog Weather Station (Model 550) installed at Indian Institute of Technology (IIT), Delhi. The instrument, which includes a cup anemometer, records wind speed and direction at height of $20 \mathrm{~m}$ from ground level. Measurement of particulate matter concentration was carried out through GRIMM Aerosol Spectrometer (Model 1.108). 24-hour average data for $\mathrm{SO}_{2}$ and $\mathrm{NO}_{2}$ concentrations was collected from Sirifort monitoring station of Central Pollution Control Board which is the regulatory authority in the state and is close to IIT $(\sim 2 \mathrm{~km})$.

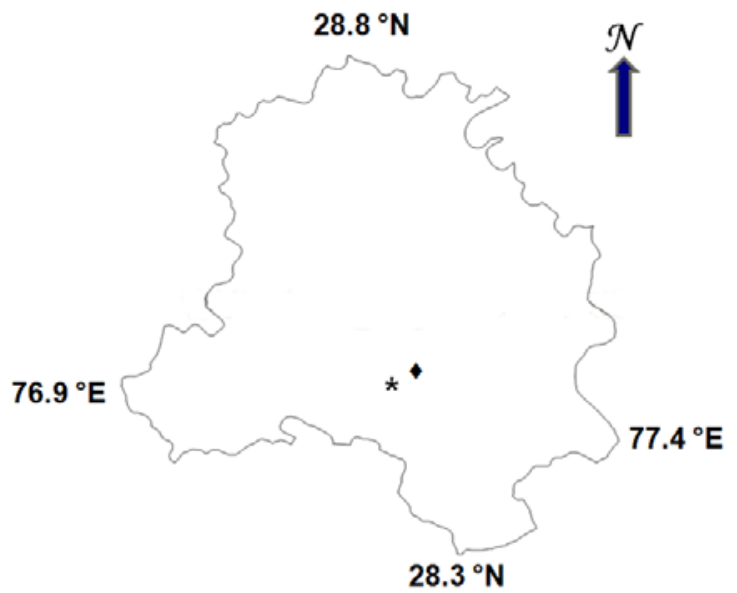

* IIT - Siri Fort Monitoring Station

Figure 1: Study Area of Delhi.
The wind speed and direction data for Mumbai has been derived from http://www.wunderground.com. This website collects weather conditions directly from weather stations located in various countries which are owned by government agencies and international airports. For Mumbai, the data is collected from the aeronautical weather station of Indian Meteorological Department (IMD) located at Chhatrapati Shivaji International Airport in Mumbai $\left(19.1^{\circ} \mathrm{N}, 72.8^{\circ} \mathrm{E}\right)$. This weather station is a part of WMO World Weather Information Service and thus data is available in public domain. The air quality data in respect of hourly average ambient $\mathrm{SO}_{2}, \mathrm{NO}_{2}$ and $\mathrm{PM}_{10}$ concentrations has been collected from the online air quality database of Central Pollution Control Board at Parel that is closest to the airport weather station.

\section{Methodology}

Stagnation, recirculation and ventilation are determined by integral quantities such as wind run (S) and recirculation factor (R). The wind run is the total distance a parcel would travel regardless of direction, over a transport time under consideration while recirculation factor, as the name suggests, provides an indication of the presence of local recirculation on the time scale comparable with transport time. The recirculation factor $\mathrm{R}$ gives an indication of the presence of local recirculation [22]. The approach proposed by Allwine and Whiteman [1] has been adopted in the present study for calculation of daily wind run $(S)$ and recirculation factor $(\mathrm{R})$ from hourly averaged wind vectors.

Wind, being a vector quantity, can be resolved into a horizontal component (east-west) and a vertical component (north-south). Let us suppose we have $N$ data points over a desired transport time $\tau$ with $T$ as averaging interval of data. For a given wind speed $U$ and meteorological direction $\theta$ (measured from north), the wind components are expressed as

$$
\begin{aligned}
& \mathrm{n}_{\mathrm{i}}=\mathrm{U}_{\mathrm{i}} \cos \left(\mathrm{D}_{\mathrm{i}}-180\right) \\
& \mathrm{e}_{\mathrm{i}}=\mathrm{U}_{\mathrm{i}} \sin \left(\mathrm{D}_{\mathrm{i}}-180\right)
\end{aligned}
$$

where $n_{i}$ and $e_{i}$ represent north-south and east-west component respectively for each discrete data point $i$. If we have hourly values of $\mathrm{U}$ and $\theta$, we can sum equations (1) and (2) over 24 hours to get daily north-south and east-west transport distance as

$$
\begin{gathered}
X_{i}=T \sum_{i=1}^{i+p} n_{i} \\
X_{i}=T \sum_{i=p}^{i+p} e_{i}
\end{gathered}
$$

where $\mathrm{i}=1, \ldots, N-p ; \mathrm{p}=\tau / \mathrm{T}-1$

The resultant transport distance is computed as

$$
L_{i}=\sqrt{X_{i}^{2}+Y_{i}^{2}}
$$

while wind run (total distance traveled) is computed as

$$
S_{i}=\tau \sum_{i=p}^{i+p} U_{j}
$$

The recirculation factor is calculated as

$$
R_{i}=1-\frac{L_{i}}{S_{i}}
$$

Thus using above equations, we can compute individual daily wind run and recirculation factor.

When $\mathrm{R}$ is equal to 0 , straight-line transport has occurred with no recirculation; when $\mathrm{R}$ is equal to 1 , zero net transport has occurred over the time interval under consideration, and there has been a complete recirculation where the air parcel has returned to its origin. The wind 
run is used as a measure of stagnation; a value of $S$ equal to 0 is the theoretical value defining total stagnation, that is, no winds and thus no transport. Ventilation is characterized by low values of $\mathrm{R}$ and high values of S. Classification of atmosphere under these different events is achieved by comparing the mean values of the wind run $\mathrm{S}$ and of the recirculation factor $\mathrm{R}$, with predetermined critical values.

Thus if

\section{$\mathrm{S} \leq \mathrm{S}_{\mathrm{c}}$ : site is prone to stagnation}

$\mathrm{R} \geq \mathrm{R}$ : site is prone to recirculation, and if

$\mathrm{S} \geq \mathrm{S}_{\mathrm{cv}}$ and $\mathrm{R} \leq \mathrm{R}_{\mathrm{cv}}$ : site is prone to ventilation

Here $\mathrm{S}_{c}$ and $\mathrm{R}_{c}$ are the average daily pre determined critical transport indices (CTIs) for stagnation and recirculation, respectively, and $\mathrm{S}_{\mathrm{cv}}$ and $\mathrm{R}_{\mathrm{cv}}$ are the average daily CTIs for ventilation. Allwine and Whiteman [1] proposed daily CTIs as $S_{c}=170 \mathrm{~km}, \mathrm{Rc}=0.4, \mathrm{~S}_{\mathrm{cv}}=250$ $\mathrm{km}$, and $\mathrm{R}_{\mathrm{cv}}=0.2$. This approach and the CTIs values have been used in various subsequent similar studies [2-4].

\section{Results and Discussion}

\section{Wind flow conditions over Delhi}

Figures 2 (a) and (b) display the results in form of percentage occurrence of stagnation and recirculation events. Clearly, the city airshed is prone to stagnation as the stagnation events have dominant presence throughout the study period. The months of December 2007 and February 2008 observed most cases of stagnation events ( $96 \%$ and $97 \%$ respectively) while most cases of recirculation were observed in the month of May (41\%). It is important to note that ventilation conditions are altogether non-existent in the city. However, stagnation conditions are dominantly present in the city followed by some recirculation conditions at times. Season wise, the spring months observed most cases of stagnation ( $92 \%)$ followed by winter $(81 \%)$ and summer $(71 \%)$. The recirculation events, though few in occurrence, were observed mostly in summer months $(29 \%)$ followed by winter (17\%) and spring (8\%).

The above mentioned condition is because of prevalence of low/ calm winds. Overall, about $43 \%$ of total winds in the entire study period were observed to be under calm conditions $\left(<0.5 \mathrm{~ms}^{-1}\right)$. The highest speed was up to $3.6 \mathrm{~ms}^{-1}$. However, maximum frequencies of wind speeds (52\%) were under the range of $0.5-2.1 \mathrm{~ms}^{-1}$. Prevalence of calm conditions and low wind speeds supports the dominance of stagnation conditions in Delhi.

\section{Association of ambient air pollution to wind flow conditions}

Stagnation and recirculation events are expected to create high pollution favoring circumstance in Delhi city. Daily average ambient air pollution trends of $\mathrm{SO}_{2}, \mathrm{NO}_{2}, \mathrm{PM}_{10}$ are therefore studied with wind run and recirculation factors.

Wind run: Figure 3 (top panel) displays the scatter plots of wind run (top panel) with $\mathrm{NO}_{2}, \mathrm{SO}_{2}, \mathrm{PM}_{10}$ concentrations respectively. The critical wind run index for stagnation $(170 \mathrm{~km})$ and 24 hour average ambient air quality standards of pollutants for residential areas are also indicated in the figure. The figure clearly reveals that $\mathrm{PM}_{10}$ and $\mathrm{NO}_{2}$ concentrations mostly exceed the prescribed air quality standards and the wind run always below the stagnation index confirming the stagnation conditions. However, due to several air pollution control measures with respect to $\mathrm{SO}_{2}$, the concentrations are always below the standard. The values of correlation coefficient ( $r$ ) between the wind run and ambient concentrations are also indicated on the plots. As explained in previous sections pollutant concentrations are expected to be negatively correlated with the wind run. A reasonable negative correlation has been shown in this figure which is maximum for $\mathrm{NO}_{2}$ $(\mathrm{r}=-0.6)$ followed by $\mathrm{PM}_{10}(\mathrm{r}=-0.4)$ and $\mathrm{SO}_{2}(\mathrm{r}=-0.3)$. The correlation coefficient is best in terms of magnitude for $\mathrm{NO}_{2}$, followed by $\mathrm{PM}_{10}$ and $\mathrm{SO}_{2}$. Hence, other than transport, there are factors responsible for these differences. These are emissions and chemistry. Among $\mathrm{SO}_{2}, \mathrm{NO}_{2}$ and $\mathrm{PM}_{10}, \mathrm{SO}_{2}$ emissions are lowest in Delhi thereby resulting in very low levels [23]. This could be a reason why a well defined relation was not observed with $\mathrm{SO}_{2}$. Nitrogen oxides are actively involved with the atmospheric chemical reactions mainly ozone and nitrate formations. The overall lifetime of nitrogen oxides in troposphere is approximately one day [24]. This corresponds well to the average time (24 hours) considered for wind run estimations in the present study. On the other hand, atmospheric $\mathrm{PM}_{10}$ are a result of direct emissions as well as indirect formation. These reactions have varying time scales and residence/life time of resulting aerosols can range from few hours to few days before they are removed by cloud and precipitation processes [25]. Hence, we observe that (negative) correlation with stagnation/ recirculation is weaker in case of $\mathrm{PM}_{10}$ in comparison to $\mathrm{NO}_{2}$ or $\mathrm{SO}_{2}$.

Recirculation factor: Figure 3 (bottom panel) shows the scatter plots of recirculation factor obtained with $\mathrm{NO}_{2}, \mathrm{SO}_{2}$ and $\mathrm{PM}_{10}$. The line for critical recirculation factor of 0.4 above which recirculation conditions are satisfied is also shown. It can be seen that compared to wind run, recirculation events are fewer in occurrence. The correlation coefficient values obtained are -0.13 for $\mathrm{NO}_{2}, 0.04$ for $\mathrm{SO}_{2}$ and -0.1 for $\mathrm{PM}_{10}$. It can be seen that the relationship between ambient levels of pollutants and recirculation factor is not so well defined. This may be due to lower prevalence of recirculation conditions in Delhi.

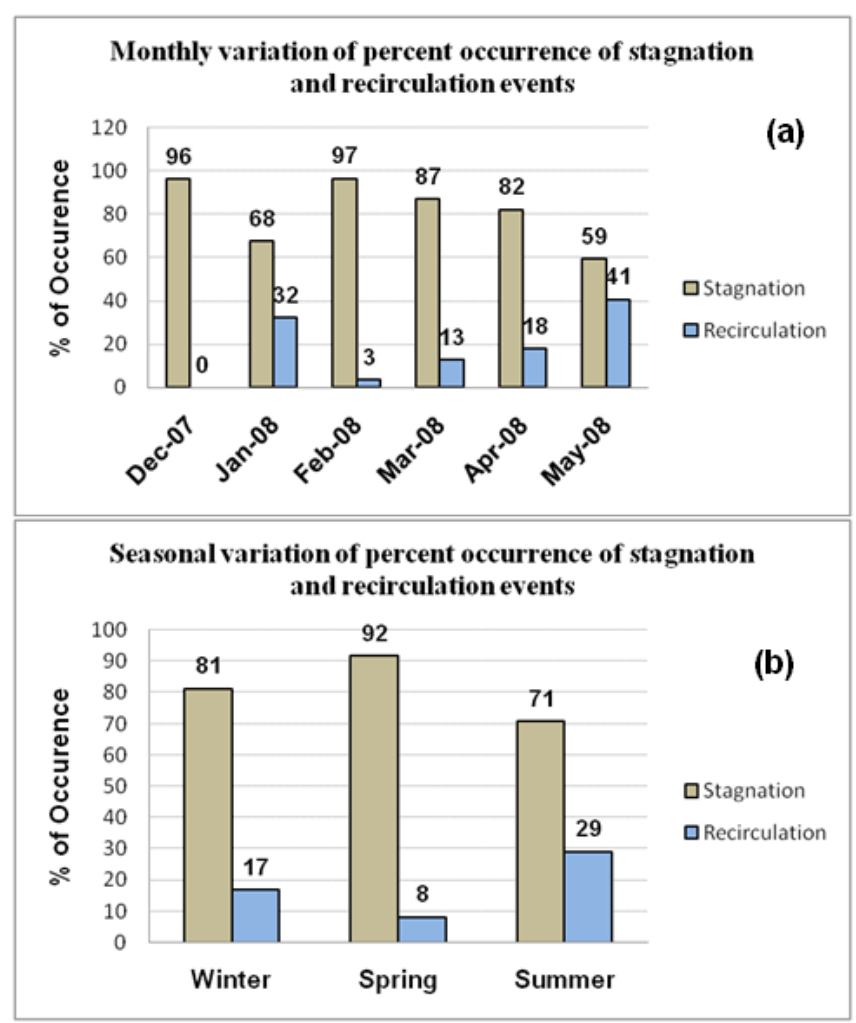

Figure 2: Variation of percentage occurrence of stagnation and recirculation events in Delhi on (a) monthly basis and (b) seasonal basis. 
There is no significant recirculation of pollutants and thus a defined relationship between recirculation factor and ambient concentration levels cannot be established. Recirculation does not necessarily mean low wind. It indicates that transport of pollutant never occurs beyond the city's limits and keeps on circulating within the city. However, lower correlation during recirculation conditions as obtained in this study mainly indicates that transport of pollutants outside of city cannot be ruled out as sources of pollution are spread all over the city.

\section{Comparisons with megacity Mumbai}

Wind speeds are higher in magnitude with hourly maximum speed ranging up to $6 \mathrm{~ms}^{-1}$. At such higher speeds ventilation events are expected with comparatively higher frequency. However, the sealand breeze also builds up recirculation thereby decreasing overall ventilation. Figure 4 (A) depicts the monthly stagnation, ventilation and recirculation scenario in Mumbai for the study period (Dec 2007May 2008) and Figure 4 (B and C) displays comparison of stagnation and recirculation in Delhi and Mumbai. Stagnation events occur less as compared to Delhi $(7-87 \%)$ while recirculation events' frequency is much higher $(7-43 \%)$. Ventilation events occur with mostly in the month of May. Table 1 lists the correlation between wind flow conditions and daily average concentrations of $\mathrm{NO}_{2}, \mathrm{SO}_{2}, \mathrm{PM}_{10}$. The concentrations obtained from the air quality station nearest to the Mumbai weather station have been analyzed. A noticeable result is that there is substantial positive correlation between recirculation factor and concentration levels which was not there in Delhi. It is the higher prevalence of recirculation events which lead to a significant relationship with concentrations in a coastal city like Mumbai.

Stagnation incidences are lower in Mumbai compared to Delhi while recirculation events are much higher. At the same time, ventilation conditions exist to some extent in Mumbai while they were virtually absent in Delhi. Now, we need to examine how these conditions affect the air quality of Mumbai. Particulate matter and $\mathrm{NO}_{x}$ are pollutants of major concern in both Delhi and Mumbai from viewpoint of ambient air quality standards. Passenger travel forms the major emission sector for these pollutants in these megacities but Mumbai registers higher emissions of particulate matter and nitrogen oxides emissions. Emissions of particulates and nitrogen oxides were about 1.6 and 2.4 times, respectively, greater in Mumbai as compared to Delhi [26]. However, this difference is not reflected in the ambient concentration levels of these pollutants in the cities. Instead, the air quality scenario is contrary to the emission pattern of the cities.

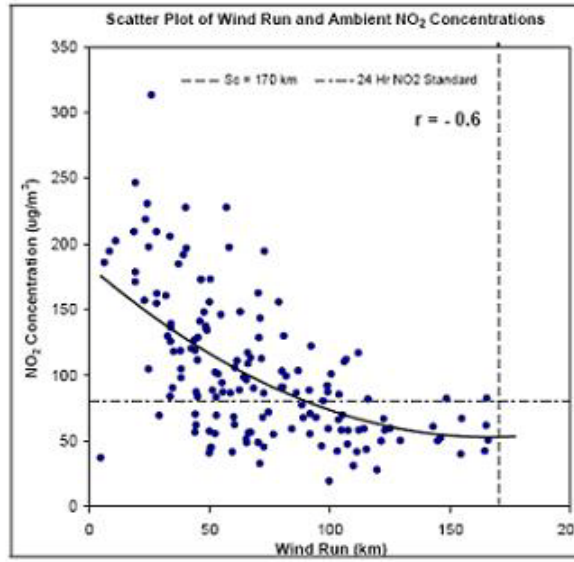

$\mathrm{NO}_{2}$

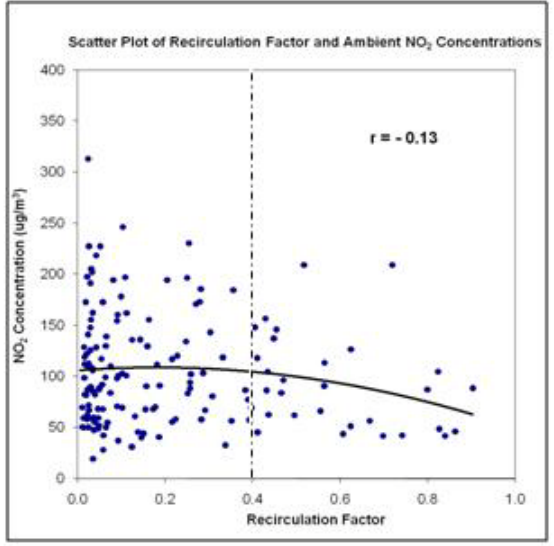

$\mathrm{NO}_{2}$

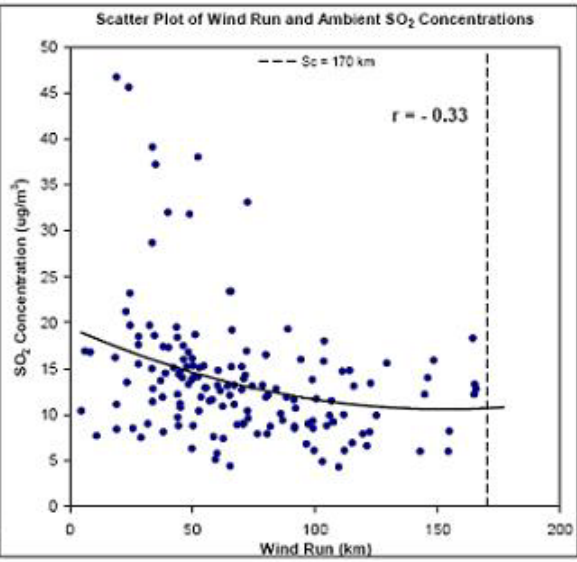

$\mathrm{SO}_{2}$

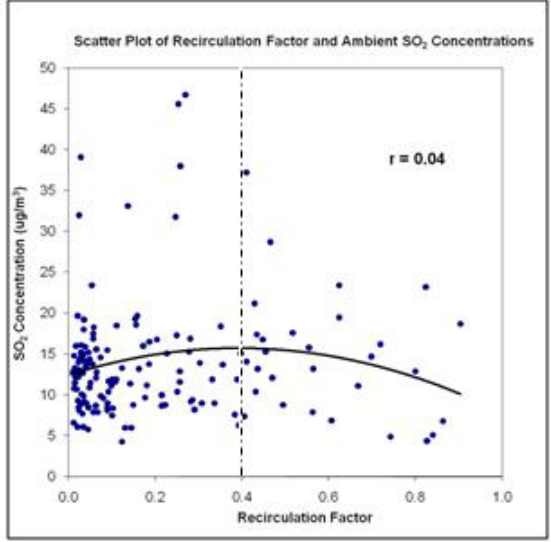

$\mathrm{SO}_{2}$

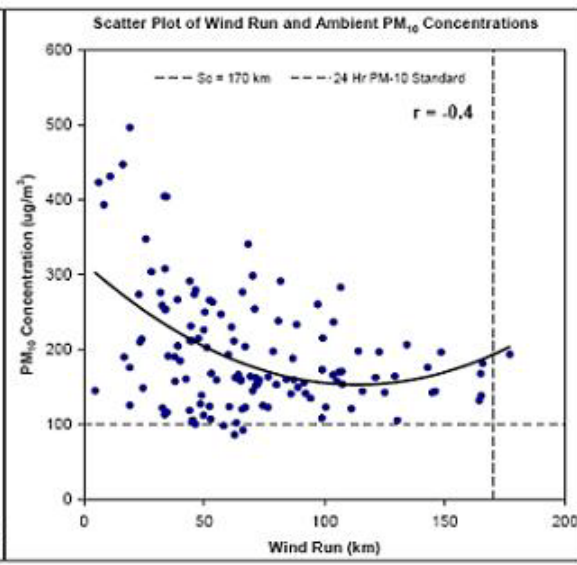

$\mathbf{P M}_{10}$

Figure 3: Scatter plots of wind run (top panel) and recirculation factor (bottom panel) with ambient concentrations of $\mathrm{NO}_{2}$, $\mathrm{SO}_{2}$ and $\mathrm{PM}_{10}$ during the experimental period in Delhi. 

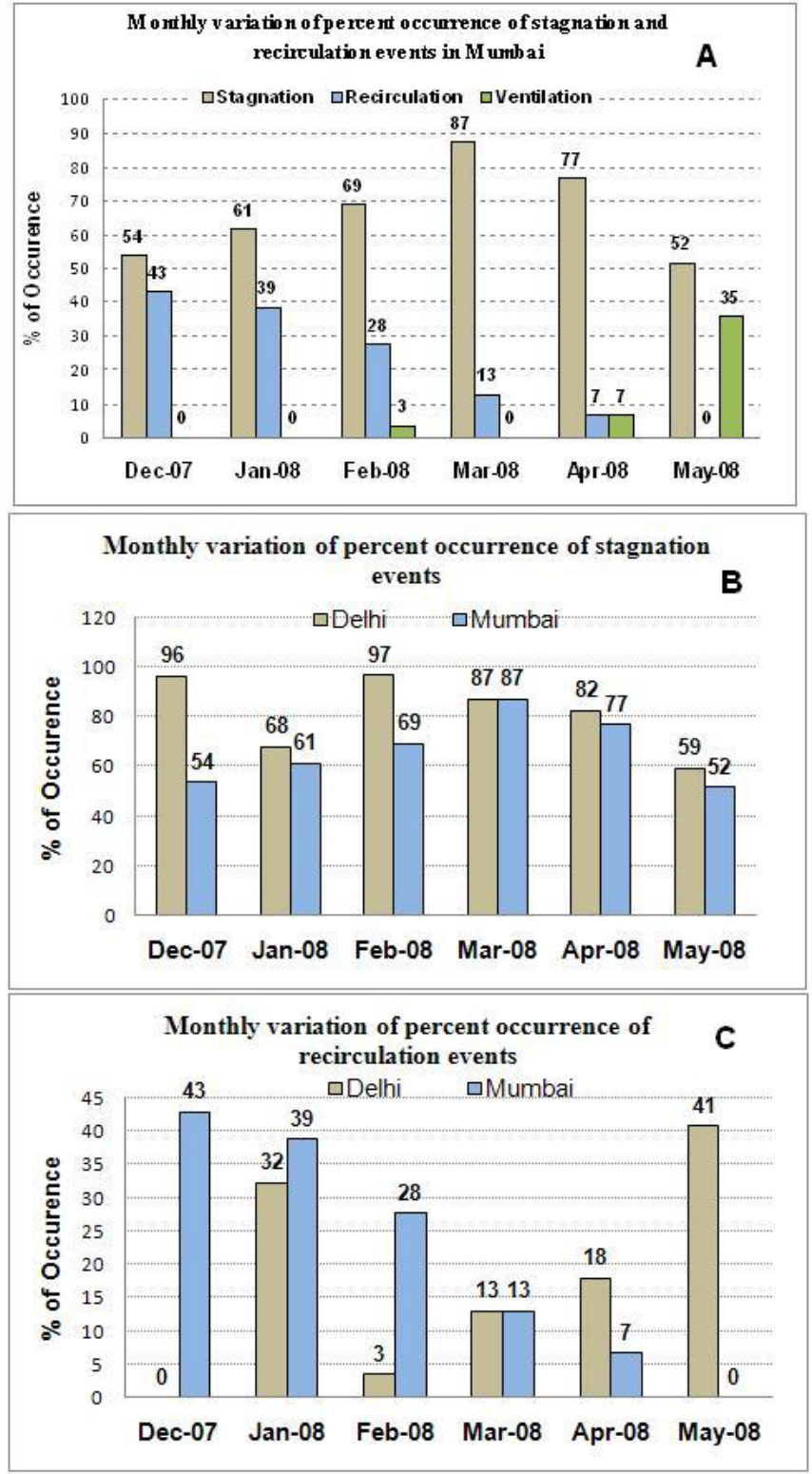

Figure 4: (A) Monthly variation of percentage occurrence of stagnation, recirculation and ventilation events in Mumbai; (B) Comparison of monthly variation of percentage occurrence of stagnation events in Mumbai and Delhi; (C) Comparison of monthly variation of percentage occurrence of recirculation events in Mumbai and Delhi.

\begin{tabular}{|l|l|l|}
\hline Pollutant & Wind Run & Recirculation Factor \\
\hline $\mathrm{NO}_{2}$ & -0.63 & 0.62 \\
\hline $\mathrm{SO}_{2}$ & -0.51 & 0.54 \\
\hline $\mathrm{PM}_{10}$ & -0.23 & 0.54 \\
\hline TSP & -0.56 & 0.71 \\
\hline
\end{tabular}

Table 1: Correlation Coefficient Matrix of wind run and recirculation factor with daily average pollutant concentration levels in Mumbai.

Figure 5 depicts plots of wind run and ambient $\mathrm{PM}_{10}$ and $\mathrm{NO}_{2}$ levels in the two cities on those days for which maximum dataset is available for both the cities. Mumbai is exposed to relatively lower levels of these pollutants despite having higher emissions. This can be attributed to higher wind runs generally prevalent in the city. Another considerable observation is the dominance of wind run over recirculation factor in influencing concentration levels. The notable feature here is overall greater recirculation ventilation conditions in Mumbai in comparison to Delhi where ventilation conditions dominate in case of former perhaps due to nearing monsoon season and proximity to the sea coast. Overall, in Delhi there are more stagnation conditions and low winds while Mumbai has greater ventilation and recirculation events. $\mathrm{PM}_{10}$ concentrations are closer to ambient standards in Mumbai. However, in Delhi they are much higher as is evident from the figure. $\mathrm{NO}_{2}$ concentrations are generally below the air quality standard in Mumbai while it is well above the standard in case of Delhi.

Thus, this intercity comparison has revealed how wind flow conditions significantly influence the concentration levels. The comparison was limited to pollutant levels in two cities where the population demographics and pollution emission sources are more or less similar. In cities with very high emissions, role of wind flow conditions may be less superimposing for such comparison. Pollution levels are likely to be linked to wind run, because concentration levels are inversely proportional to the scalar wind speed. The link between the recirculation factor and concentration is much more indirect and thus more tenuous. These expectations are borne out by the weak correlations between these factors and concentrations of $\mathrm{SO}_{2}, \mathrm{NO}_{2}$, and $\mathrm{PM}_{10}$. Nonetheless, the study has shown how high emissions coupled with stagnation favoring circumstances have made Delhi prone to poor air quality. It also reinforces the need to curtail pollutant emissions in Delhi as meteorology can't be altered easily by human intervention.

\section{Conclusions}

Climatic conditions of Delhi favor high atmospheric pollution potential as demonstrated by the strong dominance of stagnation conditions (more than 90\%) and its correlation with the air quality status of the city. However, poor correlation between recirculation and pollution was observed in Delhi. Comparison with another Indian megacity Mumbai shows that despite of higher emissions than Delhi, Mumbai has better air quality attributed mostly to more prevalence of ventilation conditions. As demonstrated in this study, higher pollution potential for an urban airshed could lead to poorer air quality even with lower emissions in comparison to a city with lower pollution potential and higher emissions. Therefore urban planners should always involve such analysis of wind flow conditions vis-à-vis impact on air quality issues for location and designing of cities. Carrying capacities of the cities and their ranking for pollution potential shall be undertaken based on long term climatology with due consideration to wind flow conditions a-priori for various urban airsheds before major developmental activities are chosen.
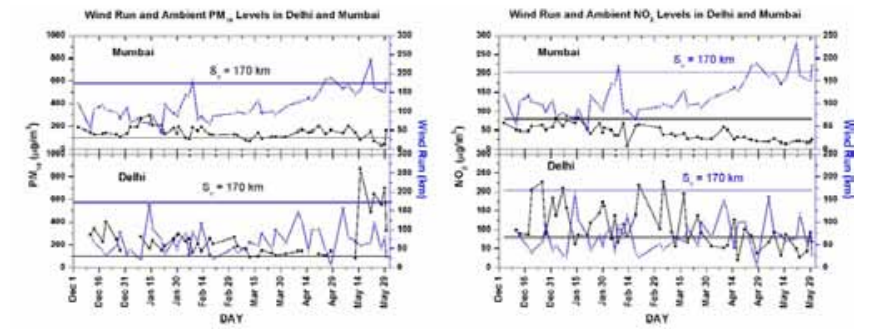

Figure 5: Plots of wind run and ambient PM10 (left) and NO2 (right) levels in Delhi and Mumbai. 
Citation: Mohan M, Bhati S (2012) Wind Flow Conditions as an Indicator to Assimilative Capacities of Urban Airsheds towards Atmospheric Pollution Potential. J Civil Environ Eng S1:003. doi:10.4172/2165-784X.S1-003

\section{Acknowledgements}

The authors acknowledge the partial financial support of Ministry of Human Resource Development (MHRD), Government of India for this study through the research project "Quantitative Risk Assessment from Acute and Chronic Exposure of Fine Particulate Matter Due To Anthropogenic Emissions in the Urban Environment of Mega City Delhi".

\section{References}

1. Allwine KJ, Whiteman CD (1994) Single-station integral measures of atmospheric stagnation, recirculation and ventilation. Atmos Environ 28: 713721.

2. Venegas LE, Mazzeo NA (1999) Atmospheric stagnation, recirculation and ventilation potential of several sites in Argentina. Atmos Res 52: 43-57.

3. Kim EH, Suh KS, Hwang WT, Jeong HJ, Han MH, et al. (2007) Analysis of the site characteristics of Korean nuclear power sites from the meteorological aspects. Ann Nucl Energy 34: 719-723.

4. Nankar DP, Patra AK, Dole MU, Venkataraman S, Hegde AG (2009) Atmospheric stagnation, recirculation and ventilation characteristics at Kakrapar atomic power station site. Ann Nucl Energy 36: 475-480.

5. Zhao Z, Chen S-H, Kleeman MJ, Mahmud A (2011) The Impact of Climate Change on Air Quality-Related Meteorological Conditions in California. Part II: Present versus Future Time Simulation Analysis. J Climate 24: 3362-3376.

6. Pérez I, Sánchez M, García M, Paredes V (2011) Relationship between $\mathrm{CO}_{2}$ at a rural site and integral measures of atmospheric stagnation, recirculation, and ventilation. Naturwissenschaften 98: 565-574.

7. Pasch AN, MacDonald CP, Gilliam RC, Knoderer CA, Roberts PT (2011) Meteorological characteristics associated with PM2.5 air pollution in Cleveland, Ohio, during the 2009-2010 Cleveland Multiple Air Pollutants Study. Atmos Environ 45: 7026-7035.

8. Tai APK, Mickley LJ, Jacob DJ (2010) Correlations between fine particulate matter (PM2.5) and meteorological variables in the United States: Implications for the sensitivity of PM2.5 to climate change. Atmos Environ 44: 3976-3984.

9. Brinkhoff T (2008) The Principal Agglomerations of the World

10. CAI (2010) India: Air Quality Profile.
11. CPCB (2009) Annual Report 2008-2009, Central Pollution Control Board (CPCB), Delhi, India.

12. Mohan M, Kandya A (2007) An Analysis of the Annual and Seasonal Trends of Air Quality Index of Delhi. Environ Monit Assess 131: 267-277.

13. Mohan M, Bhati S, Rao A (2011) Application of air dispersion modelling for exposure assessment from particulate matter pollution in mega city Delhi. AsiaPac J Chem Eng 6: 85-94.

14. Gurjar BR, Jain A, Sharma A, Agarwal A, Gupta P, et al. (2010) Human health risks in megacities due to air pollution. Atmos Environ 44: 4606-4613.

15. Mohan M, Dagar L, Gurjar B (2007) Preparation and Validation of Gridded Emission Inventory of Criteria Air Pollutants and Identification of Emission Hotspots for Megacity Delhi. Environ Monit Assess 130: 323-339.

16. Gurjar BR, van Aardenne JA, Lelieveld J, Mohan M (2004) Emission estimates and trends (1990-2000) for megacity Delhi and implications. Atmos Environ 38: $5663-5681$

17. Mohan M, Dube M (2001) Ambient air quality assessment of sulphur dioxide over Delhi. Indian J Environ Prot 21: 720.

18. DES (2006) Statistical Handbook of Delhi-2006. Directorate of Economic Survey, Govt of NCT of Delhi, Delhi.

19. Das PK (2002) The Monsoons, National Book Trust, India.

20. World Gazetteer, 2009. India: largest cities and towns and statistics of their population. http://world-gazetteer.com, Accessed 17 June 2011

21. Mumbai on the net (2012) Mumbai City Weather

22. Kumar D, Kumar A, Kumar V, Rao KS, Kumar J, et al. (2011) Study of atmospheric stagnation, recirculation, and ventilation potential at Narora Atomic Power Station site. Radiat Prot Environ 34: 104-109.

23. Mohan M, Bhati S, Gunwani P, Marappu P (2012) Emission Inventory of Ai Pollutants and Trend Analysis Based on Various Regulatory Measures Ove Megacity Delhi.

24. Jacob DJ (1999) Introduction to Atmospheric Chemistry. Princeton University Press.

25. Husar RB, Patterson DE (1980) Regional scale air pollution: sources and effects. ann ny acad sci 338: 399-417.

26. Guttikunda S (2009) Motorized Passenger Travel in Urban India: Emissions \& Co-Benefits Analysis. SIM-Air Working Paper Series, India. 